\title{
Some Open Problems in Cooperative Games
}

\section{Cesarino Bertini, Gianfranco Gambarelli, Izabella Stach*}

\begin{abstract}
In this paper we highlight some problems, still open before us, concerning the theory and application of cooperative games.
\end{abstract}

Keywords: cooperative games; power indices; finance; politics; voting

\section{Introduction}

In some previous publications we presented several open problems that we have "on our tables", regarding different areas of the theory of cooperative games and related applications. The aim of this work is to put together these works in a single document, in order to allow a complete and organic presentation. The abovementioned papers that we have brought together in this work are (Fragnelli, Gambarelli 2014), (Bertini et al. 2013a, 2013b and 2015).

The wide use of self-quotation does not derive from the belief that the open problems mentioned in our papers are of particular importance compared with others, but simply from the better knowledge that we have of the problems, which we are working on.

The paper is organized as follows: Section one is devoted to some theoretical topics, i.e. a link between two general forms of games (Subsection 1.1) and values of games as baricenters (Subsection 1.2). In Section two we present some general models, each of which has different fields of application: collusion (Subsection 2.1), interfering elements (Subsection 2.2) and power indices (Subsection 2.3). Then we deal with several applications: to international economics (Section three), to marketing cooperatives (section four), to Finance (Section five) and to Politics (Section six).

\section{Theory}

This section contains theoretical topics: links between two general forms of games, and game values as baricenters.

\footnotetext{
* Cesarino Bertini, Department of Management, Economics and Quantitative Methods, University of Bergamo, Italy, e-mail: cesarino.bertini@unibg.it; Gianfranco Gambarelli, Department of Management, Economics and Quantitative Methods, University of Bergamo, Italy, e-mail: gambarex@unibg.it; Izabella Stach, AGH University of Science and Technology, Faculty of Management, Krakow, Poland e-mail: istach@zarz.agh.edu.pl.
} 


\subsection{A link between two forms of games}

There are three main forms used to represent games: normal form, extensive form and characteristic function form. In (1944) John von Neumann and Oskar Morgenstern created a connection between the extensive form and the normal form of a game by means of a transformation from the first to the second. In this operation, some information is lost, but, in general, the research on these two forms of games has developed, to a certain extent, along parallel lines. On the other hand, as far as games presented in a characteristic function form are concerned, the two authors formulated a transformation to the normal form, but only for constant sum games. Due to the lack of a general transformation, the development of the theory of games in the characteristic function form proceeded separately, with its logic leaning more towards the satisfaction of the requirements of the various coalitions, thus losing sight of the strategic aspect of the players' choices. More recently, the transformation of games in characteristic function form to the normal form has been generalized to variable sum games in (Gambarelli 2007). This has enabled:

- - to bring strategic choices back into the hands of the players;

- - to start using many results from the literature (because, as previously mentioned, the normal form and the games in the characteristic function form had previously been studied using completely different methods);

- - to define particularly stable solutions for games in the characteristic function form, i.e. a Nash equilibrium leading to Pareto optimal payoffs. The existence of such a solution has been proved for all inessential games, all sub-additive games, all two-person games and all n-person games having the interior of the core empty. A game lacking such a solution has yet to be found.

In the paper introducing this transformation, various problems were left open concerning, for instance, cases in which coalitions are not equiprobable. The main issues, however, relate to the existence and the uniqueness of the solution. Regarding existence, either a general theorem is to be found, or the class of games, for which the solution is empty, must be identified. Regarding uniqueness, some criteria for restricting the set of solutions could be studied. The achievement of existence and uniqueness would lead to a game value, which would be particularly stable, due to the above-mentioned features of this solution.

\subsection{Values of games as baricenters}

It is easy to prove that the Shapley value (1953) of each two-person game coincides with the baricenter of the set of its imputations. This also occurs for all constant-sum three-person games, but not in general. In (Gambarelli 1990) a simplex of an n-dimensional Euclidean space has been set up, the vertices of which are located at particular points representing the game. The baricenter of this simplex coincides with the Shapley value in all possible games. An algorithm for the automatic computation of this value, based on such a construction, has been proposed. This algorithm employs a quick stop theorem. 
This result has been extended by Palestini (2005) to the Banzhaf value, but no analogous generalizations are known for other values.

\section{General models for multiple applications}

This section contains some general models, each with various fields of application: collusion, interfering elements and power indices.

\subsection{Collusions}

There are many contexts in which subjective evaluations need to be synthesized. For example this occurs for the judgments of artistic sports' performances (skating, diving, synchronized swimming and so on), for the evaluation of projects or objects, in banking (LIBOR, EURIBOR and so on), in finance (e.g. company quotations), in insurance (e.g. made-tomeasure policies), in the artistic field (e.g. singing and music competitions), and so on. Classical statistical methods (mean, median, trimmed means and so on) can bring misleading results when applied to asymmetric queues. The problem may become more critical in the case of collusion among some suppliers of such data. Consider, for instance, the following scores supplied by a commission of six judges for a performance:

$$
2,7,7,8,9,9 \text {. }
$$

Common sense would reason that the first judge's score is clearly discrepant from the other five scores. As such, it would seem reasonable to discard that score and take into account all of the others, thus obtaining the final score:

$$
(7+7+8+9+9) / 5=8 .
$$

But classical statistical methods lead to other results: 7 (arithmetic mean), 7.75 (2/3 trimmed mean, obtained by ignoring the highest and lowest scores), 7.50 (1/3 trimmed mean, obtained by ignoring the two highest and two lowest scores, and median).

By means of the Coherent Majority Average, introduced in (Gambarelli 2008), it is possible that judges pinpoint the exaggerated scores, even if they are all from the same side, obtaining, in the case of example, the result of 8 suggested by common sense.

This method is based on the assumption that the majority of judges are reliable. However, this assumption may fall short if the jury is divided into sub-juries. In fact, in these cases a certain sub-jury may consist of a number of colluding judges that form a majority in the sub-jury itself. To overcome these problems, the Anti Collusion Average was introduced in (Bertini et al. 2010) and applied in (Gambarelli et al. 2012). This average is based on an index of collusion assigned to each jury according to the scores given during the whole competition. 
The problem is to evaluate to what extent these new methods are better than the traditional ones adopted so far. To solve this problem, cooperative games in characteristic function form could be used, according to the following idea of Uristani (see Bertini et al. 2010)): for each type of assessment method, a game is created; then, a score is assigned to each group of referees. This score corresponds to the maximum distortion of the result that the group itself could award based on strategic evaluations, if that method were adopted. For each game devised in this way, the characteristic function can give important information. For instance, if it is sub-additive or inessential, then there is no advantage from the judges colluding. Elsewhere, other properties can help in the evaluation of a rule.

\subsection{Interfering elements}

Doses of interfering drugs are normally dispensed by a doctor, with subsequent adjustments made while keeping a patient monitored. The decision regarding the first dosage is particularly delicate, as the doctor does not always have enough information at hand. Many decisions in other applicative fields must take into consideration the effects that two elements can produce if they are used together. For example, in economics, the demand for a commodity may be influenced by the presence on the market of another commodity with synergic or antagonistic effects. Other cases occur in social choices, for instance in the taxation of various goods (agriculture, zoo technology, etc.). When two factors are introduced, there is often a primary interest concerning the effects of one rather than the other. If, for example, the importance of one factor is ten times greater than that of the other, this must be taken into account when calculating the quantities to be used. Considering the above, a recent model enables the optimum quantities of two interfering factors to be directly calculated (rather than obtained by successive approximations). This computation also accounts for the minimum quantities that are in any case to be assigned (see Carfì et al. 2013 and Carfì, Gambarelli 2015). A method is provided for all cases of continuous effect functions; furthermore, appropriate calculus techniques are given.

Unsolved problems concern methods for non-continuous functions, generalizations for cases of more than two interfering elements and new implementations of the model in the area of cooperative games. The latter refer, for example, to those cases in which the elements are dispensed by various bodies, each of which is interested in optimizing its own specific objective.

\subsection{Power Indices}

Power indices were born before game values and were identified with them (in the case of simple games) in (Shapley, Shubik 1954). From then onwards, power indices and values assumed a particular relevance in all of those games in which the core (also born during those 
years) is empty. Later, other solution concepts were introduced for such situations, but power indices continued to be considered as the basis. As a consequence power indices proliferated to the point that users, uncertain about which to employ in their own applications, began to consider them with little suspect. For purposes of clarification, a comparison of many such indices was undertaken by Bertini et al. (2013a, 2013b), Bertini and Stach (2015), and Freixas and Gambarelli (1997). In these papers many of the most known power indices have been studied and compared among each other, from the viewpoint of several properties. For a few indices the fulfilment of these properties has not been proved yet, and remains as open problems.

Another problem concerns the calculation of power indices in cases of indirect control. For example, this happens when an investor has a share in a certain company, which, in turn, holds shares in another company and so on. Another case is that of a political party consisting of currents and sub-currents. In situations of this kind, it may be useful to calculate the power of a member in the whole system. The problem has been tackled in (Gambarelli, Owen 1994) by transforming the set of inter-connected games into just one game, using the multi-linear extensions introduced by Owen in (1972). The power index that is believed to be the most suitable for describing the situation at hand can then be applied to the unified game.

In certain inter-connected games there may be "loops": for example, if company A holds shares in company B, which also holds shares in company A. The transformation described above works for all cases without loops and for some cases with loops, but not in general. Moreover, an algorithm for the automatic computation of indirect power indices was introduced by Denti and Prati in (2004), but this method could be improved to reduce the computation time.

\section{Applications to International Economics}

Developing countries often run up debts with important banking institutions, that they are then unable to pay back. In these cases, the real value of the debt decreases compared with the nominal value, to the point that, in some situations, it is worthwhile for the indebted country to buy its debt again at a lower price, to reacquire the possibility of obtaining a new credit. Many studies have been made on this subject; some in particular provide analytical models, see for instance (Gambarelli 1992).

A three-person game could be studied, the players being the indebted country, the credit institution and an international organization (such as the World Bank or the International Monetary Fund) that is concerned with settling the debt, for instance to avoid detrimental situations with a domino effect on other countries. 


\section{Applications to Marketing cooperatives}

Some manufacturers' pool together to form cooperatives, to improve the marketing of their products, for example by negotiating better prices with large buyers and sharing the risk of production losses amongst the various members. Sometimes the market price may increase after such agreements are made and, as a result, some manufacturers have an incentive to sell part of their production directly, without going through the cooperative. The cooperative may retaliate by applying previously agreed sanctions on these manufacturers. It is important to understand which are the best strategies for the cooperative (in terms of regulations to be approved) and for its individual members. A model by (Bertini et al. 2011) describes this situation and leads to a Nash equilibrium that constitutes an attractive solution.

This result opens the way to more complex models, such as oligopoly markets in which the market price falls as the supply increases.

\section{Applications to Finance}

Groups of shareholders can take over a company with a share majority. This operation can lead to considerable economic advantages. Therefore, we sometimes see share transactions that are not linked to traditional objectives of expected risk and returns, but aimed at acquiring the control of a firm. Until a few decades ago, traditional financial theories did not deal with these problems, mainly because the theory of power indices was little known in the field. The first models were developed more recently.

\subsection{Moving shares to gain control}

Some models have been devised to determine changes in an investor's power in a company following the trading of shares with others (see Gambarelli 1983). Gambarelli in (1996) proposed algorithms to compute the variations of Shapley-Shubik (1954) index and of BanzhafColeman index (Banzhaf 1965; Coleman 1971), following the exchanges of shares. These models may be useful not only to the bidder, but also to the current controller, because they enable him/her to assess the stability of his/her position in relation to potential takeovers (see Gambarelli 1993).

Some financial institutions have begun using these techniques, though obviously without divulging related results. Therefore, a comparison between theoretical models and their application remains an open problem at an official level. Furthermore, the above mentioned formulae concern the exchange of shares between two shareholders, or among one shareholder and an ocean of small shareholders who cannot control the firm. Some works regarding small shareholders who can control the firm have been developed, starting with Milnor and Shapley (1961) onwards. It would be useful to widen such research to include other types of buying and selling. 


\subsection{Portfolio Theory}

Some developments of the above discussed results even involve the Theory of Portfolio Selection. It is known that traditional portfolio models imply a diversification of investments to minimize risk. This diversification contrasts with the concentration of shares necessary for takeovers. A method of linking these two theories has been proposed by means of a control propensity index that can be linked to the risk aversion index (see Gambarelli 1982; Gambarelli, Pesce 2004). However, the possible developments of such a theory remain open. Moreover, analogously to what has been mentioned above, a comparison at an official level between the model and its applications is still open.

Finally, we would like to draw attention to the recent work by Crama and Leruth (2013) in which they show how techniques such as power indices are more suitable than cut-off methods for describing power-sharing among shareholders.

\section{Applications to Politics}

Regarding Politics, open problems remain in the following areas: Simulation, Forecasting and Apportionment.

\subsection{Simulation}

With regard to simulations for normative models, the same formulations used to describe variations in shareholder power can be applied to political parties. In this way, each party may obtain preliminary information, when considering changes to electoral regulations: for example, whether to extend the vote to immigrants, emigrants, youngsters, and so on. Nevertheless, in order to be applicable to politics, such models should be generalized to cases of differing affinities or hostilities in the formation of the coalition.

Other simulations that could be updated involve the enlargement of the European Parliament, with seat apportionment that not only takes population size into consideration, but also the Gross Domestic Products (see Bertini et al. 2005, 2014).

For a more detailed analysis of the contents of this section, see Gambarelli and Stach (2009).

\subsection{Forecasting}

The models provided for financial applications may be also applied to political forecasting. For example, models of indirect control may describe a situation in which parties are subdivided into tendencies. Likewise, the models of share exchanges in taking control of a firm may also be applied to power changes following a shift of votes between parties. Therefore, many of the open problems mentioned above also remain open in the context of political applications. 
A more specifically Politics-related issue concerns bicameral Parliaments. With regard to this, consider a national Parliament divided into two chambers (for example Deputies and Senators). If we apply a power index, a party may have a certain power in one chamber and a different power in the other. How can the party's overall power be determined? Moreover, if we have to take into consideration the various propensities for alliances amongst the different parties, the situation becomes even more complicated. Previous models have examined these two problems separately. A unifying model was formulated in Gambarelli and Uristani (2009). The resulting algorithm was applied to the political situation, at that time, in Belgium, the Czech Republic, France, Italy, Netherlands, Poland and Rumania, taking into account the positions of the parties along the left-right axis. The model was also applied globally to the European Union, considering each member country as an individual chamber.

The algorithm can be applied to other countries to assess the stability of current government compositions and of the distribution of the centres of power (Ministries, etc.) amongst the governing parties. However, it should be perfected with the use of various power indices, beyond the Banzhaf-Coleman index used in the paper (Banzhaf 1965; Coleman 1971).

\subsection{Apportionment}

Some classical criteria of fairness should be taken into account when building rules on seat apportionment: equal seats for equal votes, monotonicity (i.e. no fewer seats if more votes), and symmetry (i.e., independence from the order by which the parties are taken into consideration), non-exceeding rounding up and down, and so on.

Gambarelli and Hołubiec in (1990) introduced a criterion particularly linked to the principle of democracy: the minimization of power index distortion (see also Gambarelli and Owen 2002). These and other criteria seem first and foremost sacrosanct, but there are cases in which it is not possible to satisfy them, singly or jointly. Furthermore, distortions are magnified in systems with several districts, because despite complying with certain criteria within each individual district, infringements may result at the global level. A compromise solution was put forward by Balinski and Young in (1975). They suggested using a traditional method (the Highest Divisors) though adapted so as to avoid apportioning seats in a way that infringes the rounding-up criterion. However, the problem of other general infringements remained open. The minimax method of apportionment introduced by Gambarelli in (1999) has radically overturned those techniques so far adopted. In the past, after a method was chosen and applied to a real situation, tears were shed over all the criteria that were violated. The new technique overturns this procedure: first a priority order of criteria is chosen to be complied with, then all seat distributions are produced that comply with the first criterion; subsequently, all those not respecting the second criterion are eliminated from these seat distributions, and so on, until the final criterion is reached. If the application of a particular criterion leaves the set of remaining seats empty, this criterion is removed and the following 
ones are then applied and dealt with. In (2007) this method was generalized by Gambarelli and Palestini, extending it to the case of several districts. A theorem of solution existence has been found; an algorithm has been created. Nevertheless, an algorithm of this type leads to lengthy elaboration times because of the minimization metrics employed. This leaves the question of adopting alternative metrics so as to usefully reduce elaboration times.

\section{Conclusion}

As a conclusion to this work, we believe it to be useful to quote the two Special Issues on the matter edited by Fragnelli and Gambarelli (2013a and 2013b) for the reader who is interested in other open problems in Cooperative Games.

\section{Acknowledgements}

This work is sponsored by the University of Bergamo. The authors wish to thank all their co-authors (in particular, Vito Fragnelli and Josep Freixas) and all those who have developed or will develop any of these results. Special thanks goes to Gretel Gambarelli.

\section{References}

Balinski M.L., Young H.P (1975), The quota method of apportionment, "American mathematical monthly" no. 82, pp. 701-730.

Banzhaf J.F. (1965), Weighted voting doesn't work: a mathematical analysis, "Rutgers law review" no. 19, pp. 317343.

Bertini C., Freixas J. Gambarelli G., Stach I. (2013a), Comparing power indices, in Open Problems in the Theory of Cooperative Games, eds. V. Fragnelli, G. Gambarelli, Special Issue of International Game Theory Review, vol. 15 , no. 2, pp. 1340004-1-1340004-19.

Bertini C., Freixas J. Gambarelli G., Stach I. (2013b), Some open problems in simple games, in Open Problems in the Theory of Cooperative Games, eds. V. Fragnelli, G. Gambarelli, Special Issue of International Game Theory Review, 15 (2), pp. 1340005-1-1340005-18.

Bertini C., Gambarelli G., Scarelli A., Varga Z. (2011), Equilibrium solution in a game between a cooperative and its members, "AUCO Czech economic review" no. 5, pp. 162-171.

Bertini C., Gambarelli G., Stach I. (2005), Apportionment Strategies for the European Parliament, in: Power Measures III, eds. G. Gambarelli, M. Holler, Homo oeconomicus, vol. 22, no. 4, pp. 589-604 (republished in: (2013) M.J. Holler, H. Nurmi (eds.) Power, Voting, and Voting Power: 30 Years After, Heidelberg: Springer-Verlag, pp. 541-552).

Bertini C., Gambarelli G., Stach I. (2014), A method of seat distribution in the European Parliament, in Zarzadzanie przedsiębiorstwem. Teoria i praktyka 2014, ed. P. Łebkowski, AGH University of Science and Technology Press, Kraków, pp. 271-280.

Bertini C., Gambarelli G., Stach I. (2015), Some open problems in the application of power indices to politics and finance, "Homo Oeconomicus" vol. 32, no. 1, pp. 147-156.

Bertini C., Gambarelli G., Uristani A. (2010), Indices of collusion among judges and an anti-collusion average, in: Preferences and decisions: models and applications in Studies in Fuzziness and Soft Computing, eds. S. Greco, R. Marques Pereira, M. Squillante, R.R. Yager, J. Kacprzyk, Springer, Berlin-Heidelberg, pp. 195-210.

Bertini C., Stach I. (2015), On Public Values and Power Indices, in: Special Issue on Game Theory and Applications, eds. C. Bertini, P. Faliszewski, A. Paliński, I. Stach, Decision Making in Manufacturing and Services, vol. 9, no. 1 , (forthcoming). 
Carfì D., Gambarelli G., Uristani A. (2013), Balancing pairs of interfering elements, Zeszyty Naukowe Uniwersytetu Szczecińskiego nr 760, Szczecin University Press, Szczecin, pp. 435-442.

Carfì D., Gambarelli G. (2015), Balancing bilinearly interfering elements, in: Special Issue on Game Theory and Applications, eds. C. Bertini, P. Faliszewski, A. Paliński, I. Stach, Decision Making in Manufacturing and Services, vol. 9, no. 1, (forthcoming).

Coleman J. S. (1971), Control of collectivities and the power of collectivity to act, in: Social Choice, ed. B. Liberman, London: Gordon and Breach, pp. 269-300.

Crama Y., Leruth L. (2013), Power indices and the measurement of control in corporate structures, in: Open Problems in the Applications of Cooperative Games, eds. V. Fragnelli, G. Gambarelli, Special Issue of International Game Theory Review, vol. 15, no. 3, pp. 1340017-1-1340017-15.

Denti E., Prati N. (2004), Relevance of winning coalitions in indirect control of corporations, in: Essays on Cooperative Games - in Honor of Guillermo Owen, ed. G. Gambarelli, Special Issue of Theory and Decision, no. 36 : pp. 183-192.

Fragnelli V., Gambarelli G. (eds.) (2013a), Open problems in the theory of cooperative games, Special Issue of International Game Theory Review, vol. 15, no. 2.

Fragnelli V., Gambarelli G. (eds.) (2013b), Open Problems in the Applications of Cooperative Games, Special Issue of International Game Theory Review, vol. 15, no. 3.

Fragnelli V., Gambarelli G. (2014), Further open problems in cooperative games, in V. Fragnelli, V. and I. Stach, eds., A Special Issue of Operations Research And Decisions, vol. 24, no. 4, pp. 51-62.

Freixas J., Gambarelli G. (1997), Common properties among power indices, "Control and cybernetics" vol. 26, no. 4, pp. 591-603.

Gambarelli G. (1982), Portfolio selection and firms' control, "Finance" vol. 3, no. 1, pp. 69-83.

Gambarelli G. (1983), Common Behaviour of Power Indices, "International journal of game theory" vol. 12, no. 4, pp. $237-244$.

Gambarelli G. (1990), A new approach for evaluating the Shapley value, "Optimization” vol. 21, no. 3, pp. $445-452$.

Gambarelli G. (1992), Strategics for the repayment of external debt. Proceedings of the International Conference on Information and Systems, Dalian Maritime University Publishing House, Dalian, pp. 566-573.

Gambarelli G. (1993), An index of de-stability for controlling shareholders, in R. Flavell (ed.) Modelling Reality and Personal Modelling, Heidelberg: Physica-Verlag, pp. 116-127.

Gambarelli G. (1996), Takeover algorithms, in: Modelling Techniques for Financial Markets and Bank Management, eds. M. Bertocchi, E. Cavalli and S. Komlosi, Proceedings of the 16-th and 17-th Euro Working Group of Financial Modelling Meetings, Heidelberg: Physica Verlag, pp. 212-222.

Gambarelli G. (1999), Minimax apportionments, “Group decision and negotiation” vol. 8, no. 6, pp. 441-461 (republished in: (2003) J. Kacprzyk and D. Wagner (eds.) Group Decisions and Voting, Systems Research Institute, Warszawa: Polish Academy of Sciences, pp. 9-30).

Gambarelli G. (2007), Transforming games from characteristic into normal form, "International game theory review" no. 9, pp. 87-104.

Gambarelli G. (2008), The coherent majority average for juries' evaluation processes, "Journal of sports sciences" no. 26, pp. 1091-1095.

Gambarelli G., Hołubiec J. (1990), Power indices and democratic apportionments, in: M. Fedrizzi and J. Kacprzyk (eds.) Proceedings of the 8-th Italian-Polish Symposium on Systems Analysis and Decision Support in Economics and Technology, Warsaw: Onnitech Press, pp. 240-255.

Gambarelli G., Owen G. (1994), Indirect control of corporations, "International journal of game theory" vol. 23, No. 4, pp. 287-302.

Gambarelli G., Owen G. (2002), Power in political and business structures, in: Power and fairness, eds. M.J. Holler, M.E. Streit, "Jahrbuch für Neue Politische Ökonomie” no. 20, pp. 57-68, Tübingen: Mohr Siebeck.

Gambarelli G., Palestini A. (2007), Minimax multi-district apportionments, in Power Measures IV, ed. G. Gambarelli, Special Issue of Homo Oeconomicus, vol. 24, no. 3/4, pp. 335-356.

Gambarelli G., Pesce S. (2004), Takeover prices and portfolio theory, in Essays on Cooperative Games - in Honor of Guillermo Owen, ed. G. Gambarelli, Special Issue of Theory and Decision, Dordrecht: Kluwer Academic Publishers, No. 36, pp. 193-203.

Gambarelli G., Stach I. (2009), Power indices in politics: some results and open problems, "Homo Oeconomicus" (Essays in Honor of Hannu Nurmi), vol. 26, no. 3/4, pp. 417-441.

Gambarelli G., Uristani A. (2009), Multicameral voting cohesion games, "Central European journal of operations research" vol. 17 , no. 4, pp. 433-460. 
Gambarelli G., Iaquinta G., Piazza M. (2012), Anti-collusion indices and averages for the evaluation of performances and judges, "Journal of sports sciences" no. 30, pp. 411-417.

Milnor J.W., Shapley L.S. (1961), Values of large games II: oceanic games, Rand Corporation, R.M 2646, Santa Monica, CA.

Owen G. (1972), Multilinear extensions of games, "Management Science” no. 18, pp. 64-79.

Palestini A. (2005), Reformulation of Some Power Indices in Weighted Voting Games, "Homo Oeconomicus" vol. 22, No. 4, pp. 487-507.

Shapley L.S. (1953), A value for n-person games, in: Contributions to the Theory of Games II: Princeton: University Press, eds. A.W. Tucker, H.W. Kuhn, pp. 307-317.

Shapley L.S., Shubik M. (1954), A method for evaluating the distributions of power in a committee system, "American political science review" no. 48, pp. 787-792.

Von Neumann J., Morgenstern O. (1944), Theory of Games and Economic Behaviour, Princeton University Press, Princeton.

\section{WYBRANE PROBLEMY OTWARTE TEORII GIER KOOPERACYJNYCH}

Streszczenie: W artykule zostały zaprezentowane niektóre problemy, wciąż otwarte, dotyczące teorii i zastosowania gier kooperacyjnych.

Słowa kluczowe: gry kooperacyjne; indeksy siły; finanse; polityka; głosowania

\section{Citation}

Bertini C., Gambarelli G., Stach I. (2015), Some Open Problems in Cooperative Games, Zeszyty Naukowe Uniwersytetu Szczecińskiego nr 855, „Finanse, Rynki Finansowe, Ubezpieczenia” nr 74, t. 1, Wydawnictwo Naukowe Uniwersytetu Szczecińskiego, Szczecin, s. 469-479; www.wneiz.pl/frfu. 
